\title{
Increased serum proMMP-3 in inflammatory arthritides: a potential indicator of synovial inflammatory monokine activity
}

\author{
David J Taylor, Nap T Cheung, Peter T Dawes
}

\begin{abstract}
Objective-To investigate if the increased concentrations of stromelysin (MMP-3) found in the synovial fluid (SF) of patients with various arthritides reflect the concentrations in the circulation. Methods-Using a double antibody ELISA, we have measured proMMP-3 concentrations in sera from these patient groups and in others with a heightened acute phase response (APR) as a result of multiple organ failure.

Results-The median serum concentration of proMMP-3 was increased by up to ninefold in the inflammatory arthritides, but not in osteoarthritis or in patients with a heightened APR resulting from a non-chronic inflammatory condition.

Conclusion-In chronic inflammatory diseases such as rheumatoid arthritis, serum proMMP-3 may prove to be a more specific indicator of monokine activity than currently available serum markers.
\end{abstract}

(Ann Rheum Dis 1994; 53: 768-772)

Rheumatoid synovial fibroblasts exposed in vitro to the proinflammatory monokines interleukin-1 (IL-1) or tumour necrosis factor $\alpha(\mathrm{TNF} \alpha)$ produce a number of matrix metalloproteinases (MMP), including MMP$1,-2,-3$, and -9 , of which the most abundant is $\mathrm{MMP}-3$, previously called stromelysin. ${ }^{1-3} \mathrm{~A}$ similar predominance of MMP-3 over MMP-1 has recently been reported for synovial fluids (SF) from patients with rheumatoid arthritis (RA), in which the mean MMP-3 concentration was more than $40 \mu \mathrm{g} / \mathrm{ml} .{ }^{4}$ Increased fluid concentrations of MMP-3 compared with control were also found in osteoarthritis (OA), but these were only approximately $10 \%$ of those in rheumatoid fluids, ${ }^{5}$ presumably reflecting the greater involvement of inflammatory monokines in RA. Increased joint concentrations of MMPs may contribute to the pathology of these diseases as, when tested in vitro, members of this enzyme family can degrade virtually all the articular cartilage components. ${ }^{6}$ Thus MMP-3 was shown to have the potential to degrade the proteoglycan component of cartilage, ${ }^{7}$ but recent analysis of aggrecan fragments from joint fluids of patients with various inflammatory arthritides suggested a major contribution from an as yet unidentified enzyme. ${ }^{8}$ The MMPs are secreted from cells in a proenzyme form and within rheumatoid SF the majority of the MMP-3 was found to be present in this inactive form (proMMP-3). ${ }^{4}$

In this study we examined whether this localised high concentration of proMMP-3 within SF was reflected in the circulation of patients with RA. Using a double antibody ELISA developed for proMMP-3, we compared the serum concentrations in patients with both inflammatory and non-inflammatory arthritides, with those of a normal control group. We also measured proMMP-3 in paired serum and SF samples collected before intraarticular injection of steroid which, if the inflamed joint were the major source of circulatory proMMP-3, would demonstrate a significant degree of association. Furthermore, in view of thair ability to inhibit both production and action of monokines, we examined the effect on serum proMMP-3 of corticosteroids directly administered to the inflamed joints of RA patients. Finally, we compared the serum concentrations of proMMP-3 and $C$ reactive protein (CRP), because the latter is regarded as a reliable indicator of disease activity in RA. These two serum components were also measured in a group of critically ill patients with multiple organ failure who would be at the height of an acute phase response, with a markedly increased serum CRP concentration.

\section{Patients and methods}

PATIENTS AND SAMPLES

Blood samples were collected from 40 patients with RA (revised American Rheumatism Association criteria, 1987) ${ }^{9}$ attending rheumatology clinics and with either early or established disease. Early RA was arbitrarily defined as disease duration of less than 30 months. Twenty patients with a clinical diagnosis of symptomatic OA confirmed by typical radiographic changes (Kellgren/ 
Lawrence score) were also selected for the study. Twenty samples for the control were obtained from "in house" members of staff. Table 1 gives details of these groups. In addition, sera from 20 patients with ankylosing spondylitis (AS) who had symptoms consistent with the New York criteria ${ }^{10}$ and from 20 patients with reactive arthritis ( $\operatorname{ReA})$, based on clinical and laboratory findings, were assayed for proMMP-3. Paired serum and SF samples were collected before intra-articular injection of steroid in patients with various inflammatory arthritides and blood was also obtained from $13 \mathrm{RA}$ patients before and 14 days after receiving such an injection of $80 \mathrm{mg}$ of methyl prednisolone (Upjohn, Crawley, United Kingdom) into the knee. SF were centrifuged to remove cells and stored at $-20^{\circ} \mathrm{C}$ until assayed by enzyme linked immunosorbent assay (ELISA). Serum samples from a group of patients $(n=20)$ with multiple organ failure, brought on in most cases by sepsis, road traffic accident or adult respiratory distress syndrome were also assayed as a patient group with an expected increased acute phase response.

DOUBLE ANTIBODY ELISA FOR proMMP-3

Rabbit and sheep polyclonal antisera to human proMMP-3, purified from IL- $1 \alpha / T N F \alpha-$ stimulated rheumatoid synovial fibroblast culture media, ${ }^{7}$ were raised with the help of Drs D E Woolley (University Hospital of South Manchester, United Kingdom) and R Drew (The Binding Site, Birmingham, United Kingdom), respectively. Neither antisera showed any cross reactivity to MMP-1, -2 or -9 when tested by Western blotting. The IgG fraction of the rabbit antisera was isolated by column chromatography on diethylaminoethyl-cellulose, whilst the anti-proMMP-3 sheep IgG was purified by affinity chromatography using proMMP-3 coupled to Affi-Gel 10 (Bio Rad, Hemel Hempstead, United Kingdom), before biotinylation with $\mathrm{D}$ Biotinyl- $\epsilon$-aminocaproic-acid-N-hydroxysuccinimide ester (Boehringer Mannheim, Lewes, United Kingdom). Before the assay, a 96 well plate was coated overnight at $4^{\circ} \mathrm{C}$ with $200 \mu \mathrm{l}$ of rabbit anti-proMMP-3 IgG in phosphate buffered saline (PBS), followed by overnight blocking at $4^{\circ} \mathrm{C}$ with $0.5 \%(\mathrm{w} / \mathrm{v})$ bovine serum albumin (BSA) in PBS-0.05\% Tween 20 (BSA-PBS-Tween). After the wells were emptied and washed in PBS-Tween, either 100 $\mu l$ of proMMP-3 standard $(0.4-25 \mathrm{ng} / \mathrm{ml})$ in a

Table 1 Clinical features of the study patients

\begin{tabular}{|c|c|c|c|c|}
\hline Variables & Early $R A$ & Established $R A$ & $O A$ & Normal \\
\hline No. patients (M:F) & $20 \quad(8: 12)$ & $20 \quad(11: 9)$ & $(3: 17)$ & $(7: 13)$ \\
\hline Age (yr) & $46.6(15.8)$ & $57.8(17.5)$ & $59.4(15.6)$ & $36 \cdot 5(9 \cdot 2)$ \\
\hline Duration (months) & $12 \cdot 8(9 \cdot 0)$ & $121.5(73.1)$ & & \\
\hline $\operatorname{ESR}(\mathrm{mm} / \mathrm{h})$ & $35 \cdot 6(21 \cdot 3)$ & $39.6(25.6)$ & & \\
\hline $\mathrm{CRP}(\mathrm{mg} / \mathrm{l})$ & $20 \quad(21 \cdot 2)$ & $41.3(35.7)$ & & \\
\hline EMS (min) & $73.5(72 \cdot 3)$ & $55.5(55.5)$ & & \\
\hline RAL positive (No.) & 15 & 14 & & \\
\hline No. tender joints & 5 & 10 & & \\
\hline Minimum & 0 & 0 & & \\
\hline Maximum & 10 & 28 & & \\
\hline
\end{tabular}

Mean $(\mathrm{SD})$ values where applicable. $\mathrm{ESR}=$ erythrocyte sedimentation rate; $\mathrm{CRP}=\mathrm{C}$ reactive protein; EMS = early morning stiffness; RAL $=\mathrm{RA}$ latex rheumatoid factor test.
1:21 dilution of horse serum in BSA-PBSTween or serum diluted by $1: 21$ with BSAPBS-Tween was added, followed by $100 \mu \mathrm{l}$ of biotinylated anti-proMMP-3 IgG in a 1:25 dilution of normal sheep serum in $300 \mathrm{mmol} / \mathrm{l}$ $\mathrm{NaCl}, 5 \mathrm{mmol} / 1 \mathrm{CaCl}_{2}, 20 \mathrm{mmol} / \mathrm{l}$ Tris, $\mathrm{pH}$ 7.5. After overnight incubation at $4^{\circ} \mathrm{C}$, each well was washed three times in PBS-Tween and once in Tris buffered saline (TBS), then $200 \mu \mathrm{l}$ of Strept ABComplex (Dako, High Wycombe, United Kingdom) in TBS was added for 30 minutes at room temperature. After three further washings in TBS and one in $0.5 \mathrm{mmol} / 1 \mathrm{MgCl}_{2}$, and $0.1 \mathrm{~mol} / 1$ diethanolamine pH 9.6 (Mg-Di), $200 \mu \mathrm{l}$ of $1 \mathrm{mg}$ p-nitrophenyl phosphate (Sigma, Poole, United Kingdom) in Mg-Di was added to each well and, after colour development, absorbance was read at $405 \mathrm{~nm}$.

A spline curve fit was used for the almost linear plot of absorbance versus the $\log$ of doubling concentrations between 0.4 and 25 $\mathrm{ng} / \mathrm{ml}$. Two control sera, prepared by spiking normal sera with purified proMMP-3, were included in each of the 12 assays reported in this study and coefficients of variation of 7.5 and $12 \cdot 3 \%$ were obtained. Doubling dilutions of a number of RA sera into 1:21 horse serum in BSA-PBS-Tween gave linear values, confirming identical behaviour of standards and samples in the assay. The assay values of six RA sera were not affected by an additional four freeze-thaw cycles. Confirmation that the assay was indeed measuring proMMP-3 was obtained by adding an excess of sheep antiproMMP-3 IgG (Dr H Nagase, Kansas, USA), which competed to prevent binding of the biotinylated antibody, in contrast with the same concentration of normal sheep IgG, which was without effect on the assay value of 14 RA sera. Furthermore, incubating RA sera overnight at $37^{\circ} \mathrm{C}$ with an activator of proMMP-3 (2 $\mathrm{mmol} / \mathrm{l}$ aminophenylmercuric acetate) caused a marked reduction in the assay value, suggesting that MMP-3 was originally present as the proenzyme, as both antibodies recognise this form in preference to active MMP-3. SF samples were initially diluted 1:21 into BSA-PBS-Tween and then further diluted in this buffer containing 1:21 horse serum to bring them on scale.

\section{REACTIVE PROTEIN}

Serum CRP was measured in the early RA and multiple organ failure patients, using radial immunodiffusion kits generously provided by The Binding Site, Birmingham, United Kingdom.

STATISTICAL ANALYSIS

Significant differences between groups were determined by the Mann-Whitney $U$ test and the Spearman rank correlation coefficient was used to examine relationships between measurements. Samples obtained before and after intra-articular injection of steroid were compared using a signed rank test for paired samples. 


\section{Results}

MEASUREMENTS OF SERUM PROMMP-3 IN PATIENTS WITH INFLAMMATORY AND NONINFLAMMATORY ARTHRITIDES

Increased concentrations of serum proMMP-3 compared with those in a normal control group were found in patients with early RA $(p<0.002), \operatorname{ReA}(p<0.001)$, established RA $(\mathrm{p}<0.001)$ and AS $(\mathrm{p}<0.001)$, but not in patients with OA $(p=0.533)$ (fig 1$)$. In the established RA patients the median serum value of $219.7 \mathrm{ng} / \mathrm{ml}$ (range $36.4-571.6 \mathrm{ng} / \mathrm{ml}$ ) was nine times greater than that in the control group $(24.3 \mathrm{ng} / \mathrm{ml}$, range $3.9-68.8 \mathrm{ng} / \mathrm{ml})$; only three patient values were within the control range. By contrast, in both the early $\mathrm{RA}$ and AS patient groups, 12 had serum proMMP-3

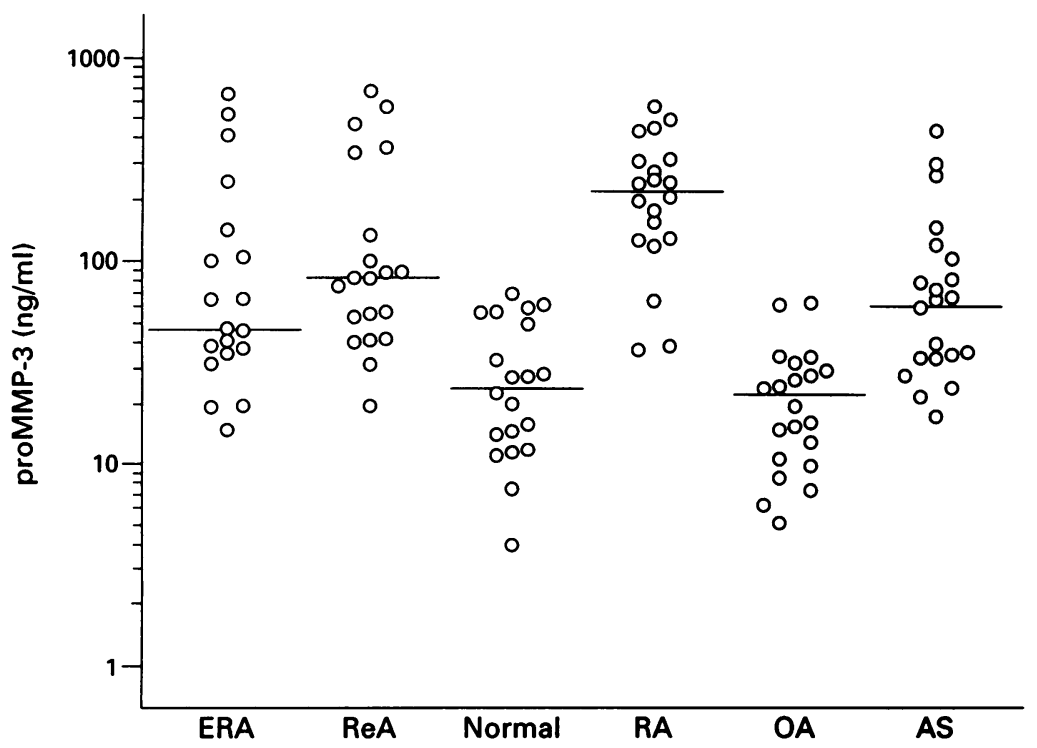

Figure 1 Serum concentrations and median values of proMMP-3 in patients with early rheumatoid arthritis (ERA), reactive arthritis $(R e A)$, established rheumatoid arthritis $(R A)$, osteoarthritis $(O A)$, ankylosing spondylitis $(A S)$ and a normal control group (Normal). There were significant differences between the inflammatory arthritides and the normal control group but not with the $\mathrm{OA}$ group.

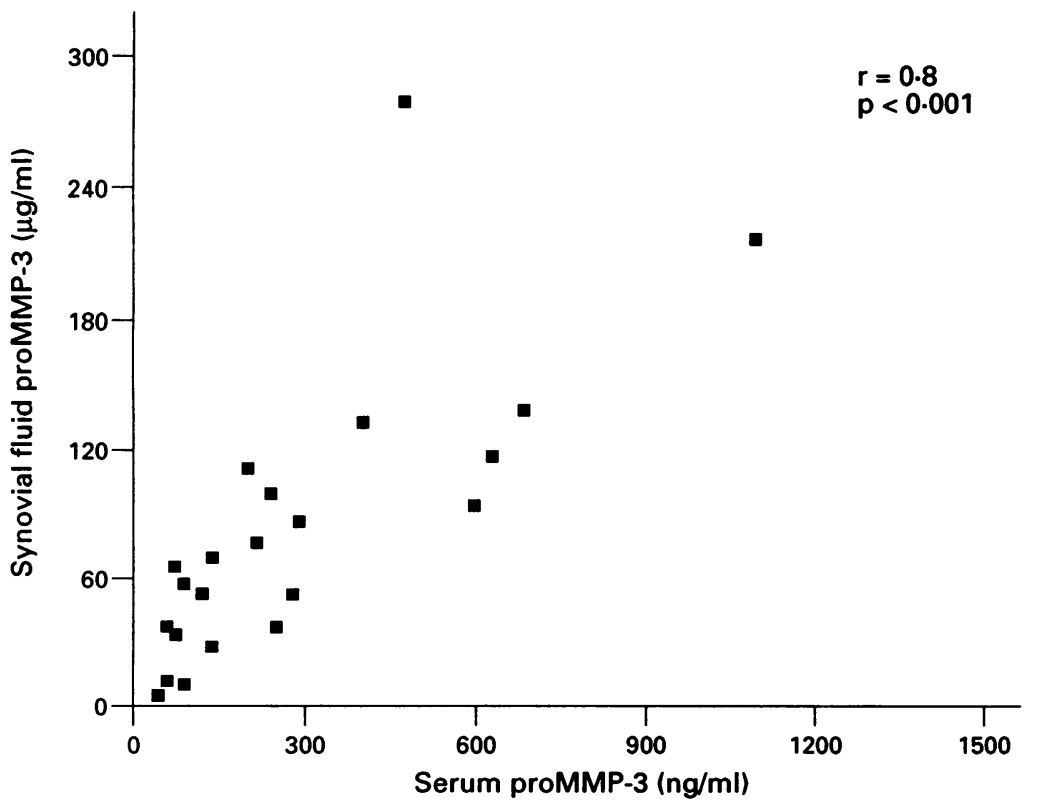

Figure 2 Concentrations of proMMP-3 in synovial fluid compared with serum from inflammatory arthritides patients before intra-articular injection of steroid. A significant correlation was obtained for these paired, simultaneously collected samples. values within the control range and median values of $47 \cdot 2 \mathrm{ng} / \mathrm{ml}$ (range $19 \cdot 4-656 \cdot 3 \mathrm{ng} / \mathrm{ml}$ ) and $61.6 \mathrm{ng} / \mathrm{ml}$ (range $17 \cdot 3-433.2 \mathrm{ng} / \mathrm{ml}$ ), respectively. OA patients had a median value of $21.3 \mathrm{ng} / \mathrm{ml}$ (range $7 \cdot 3-61 \cdot 1 \mathrm{ng} / \mathrm{ml}$ ); the ReA group had a median value of $81.9 \mathrm{ng} / \mathrm{ml}$ (range $19.5-683.0 \mathrm{ng} / \mathrm{ml}$ ) and eight patient values within the control range.

RELATIONSHIP BETWEEN SERUM AND SYNOVIAL FLUID PrOMMP-3 CONCENTRATIONS

Measurement of proMMP-3 in 22 paired, simultaneously obtained serum and SF samples collected before intra-articular injection of steroid in patients with RA or ReA revealed several-hundredfold greater concentrations within joint fluid and a significant correlation $(r=0.8, p<0.001)$ with serum values (fig 2). Western blot analysis of a $1 \%$ $(\mathrm{v} / \mathrm{v})$ dilution of seven of these fluids revealed only the doublet corresponding to the proenzyme form of MMP-3 (result not shown).

EFFECT OF INTRA-ARTICULAR INIECTION OF STEROID ON SERUM PrOMMP-3

Steroid injection into the inflamed joints of 13 patients with RA caused a significant reduction $(\mathrm{p}<0.04)$ in serum proMMP-3 (table 2). The decrease appeared most marked for those with the greatest serum concentrations before the injection.

RELATIONSHIP OF SERUM prOMMP-3 AND CRP CONCENTRATIONS

The serum concentrations of proMMP-3 and CRP in the early RA group showed a significant correlation $(r=0.48, p<0.04)$ (fig 3A). However, in a group of critically ill patients with multiple organ failure, in whom the CRP concentration was greatly increased from the normal of $<5 \mu \mathrm{g} / \mathrm{ml}$ to a median value of $134.5 \mu \mathrm{g} / \mathrm{ml}$, there was no significant correlation $(r=0.29, p=0.094)$ with serum proMMP-3 (fig 3B). Indeed, the median serum proMP-3 value of $33.8 \mathrm{ng} / \mathrm{ml}$ was not significantly different $(p=0 \cdot 159)$ from that in the normal control group.

Table 2 Serum proMMP-3 concentrations before and after intra-articular injection of corticosteroids

\begin{tabular}{|c|c|c|}
\hline \multirow[t]{2}{*}{ Patient } & \multicolumn{2}{|c|}{ proMMP-3 $(\mathrm{ng} / \mathrm{ml})$} \\
\hline & 0 & 14 days \\
\hline JP & 133.2 & $131 \cdot 3$ \\
\hline DS & $401 \cdot 3$ & $200 \cdot 3$ \\
\hline HC & 36.8 & 24.9 \\
\hline LG & 111.4 & $50 \cdot 3$ \\
\hline SP & $397 \cdot 7$ & $128 \cdot 8$ \\
\hline LR & $61 \cdot 0$ & $67 \cdot 7$ \\
\hline IU & $71 \cdot 0$ & $64 \cdot 2$ \\
\hline GF & $27 \cdot 2$ & 33.9 \\
\hline IS & 235.9 & $60 \cdot 7$ \\
\hline AK & $128 \cdot 2$ & $133 \cdot 0$ \\
\hline AS & $150 \cdot 6$ & $81 \cdot 1$ \\
\hline WF $†$ & $625 \cdot 7$ & $379 \cdot 7$ \\
\hline DS & $72 \cdot 8$ & $100 \cdot 5$ \\
\hline Median & $128 \cdot 2$ & $81 \cdot 1^{\star}$ \\
\hline
\end{tabular}

*Significantly reduced by signed rank test for paired sample $(\mathrm{p}<0 \cdot 05)$

†Both knees injected. 

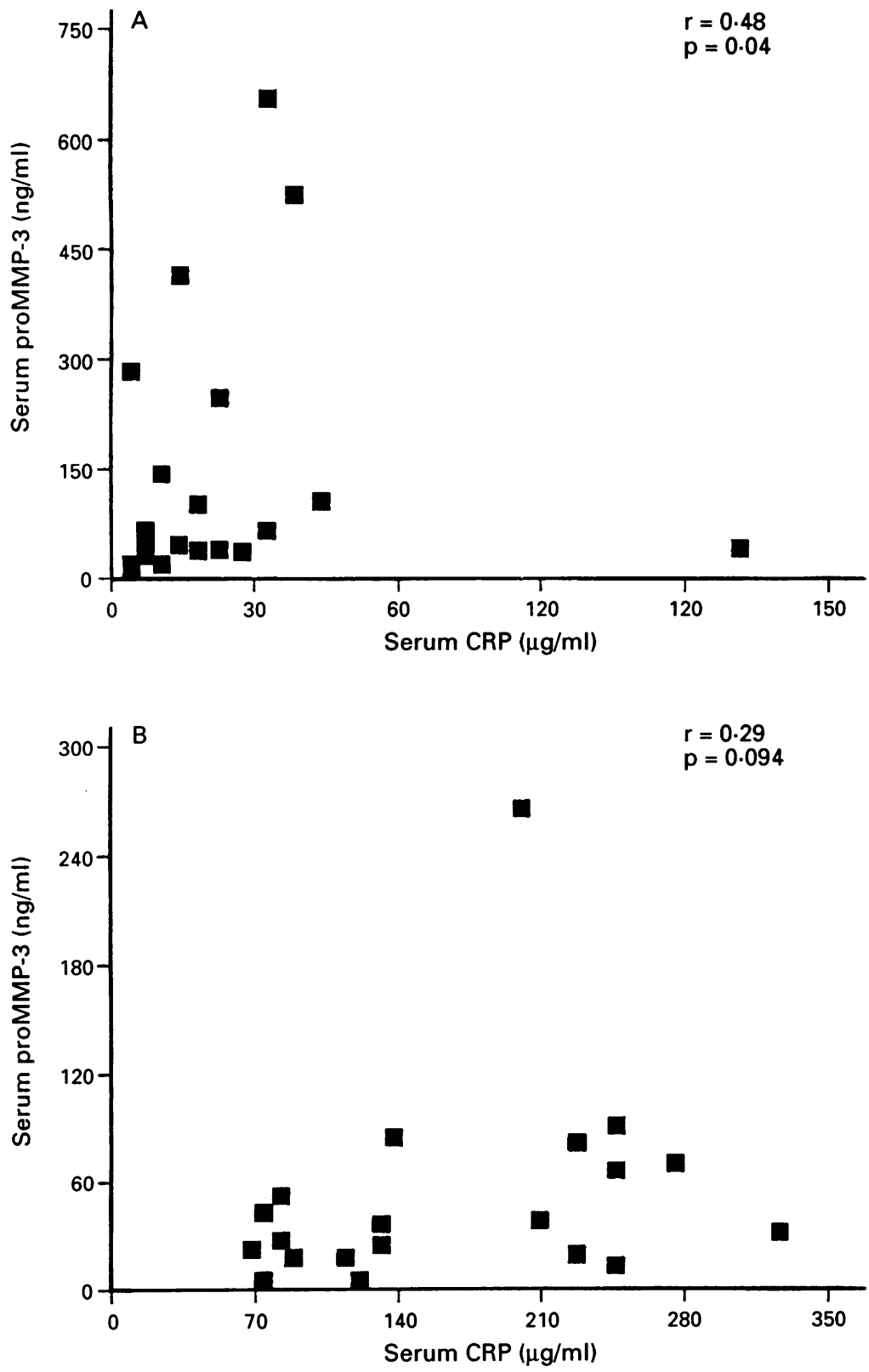

Figure 3 Relationship of serum concentrations of proMMP-3 and $C$ reactive protein $(C R P)$ in the early rheumatoid arthritis group $(A)$ and a group of patients with multiple organ failure (B). A significant correlation was obtained between these two serum components only in the $R A$ group; serum proMMP-3 was not significantly increased above normal control values $(p=0.159)$ in the patients with multiple organ failure.

\section{Discussion}

These measurements of serum proMMP-3 in patients with RA and a normal control group have demonstrated that increased concentrations of proMMP-3 are not confined to the joints of patients with this disease. ${ }^{4}$ Significantly increased median concentrations of serum proMMP-3 compared with the control group were also obtained in other inflammatory arthritides, but not in the noninflammatory condition of $\mathrm{OA}$, despite the previous report of increased joint fluid concentrations in OA. ${ }^{5}$ The marked difference between serum proMMP-3 values in RA and OA may reflect the finding in RA of approximately 10 times greater concentrations in SF and the generally greater number of joints involved than in OA. Measurement of proMMP-3 in paired, simultaneously collected serum and SF samples from patients receiving intra-articular injection of steroid indicated that the inflamed joint was indeed the source of this circulatory proMMP-3: it revealed that the SF proMMP-3 concentration was severalhundredfold greater than that in the paired serum sample, and that there was a highly significant correlation between these two values. Additionally, the intra-articular injection into RA patients of a steroid with anti-monokine properties caused a significant reduction in serum concentrations of proMMP-3, emphasising the association between joint fluid and serum concentrations. The presence of only the proenzyme (inactive) form of MMP-3 in SF agrees with previous observations ${ }^{4}$ and suggests that the material in the circulation may have no pathological effect and is merely destined for excretion via the kidneys. The finding of a much greater median serum concentration of proMMP-3 in patients with established RA than in those with recently diagnosed RA suggests the serum value may be affected by the amount of inflammatory tissue present within the joints. Within a rheumatoid joint, the synovial pannus is likely to be the major source of proMMP-3 and as this increases over the years of this chronic disease, it may well result in increased release of proMMP-3 into the SF. Furthermore, the observation that only three of the RA patients with established disease had serum values within the control range suggests that current therapy (all on second line drugs) was largely failing to reduce proMMP-3 production back to normal.

One serum marker which has gained broad acceptance as an indicator of disease activity in $R A$ is $C$ reactive protein, even though it is produced not in the joint but in the liver, being a member of the class I acute phase proteins. ${ }^{11}$ Within the recently diagnosed RA group, a significant correlation was obtained between serum CRP and proMMP-3, suggesting the latter may also be indicative of disease activity. An association between the synthesis of a class I acute phase protein and proMMP-3 in RA is perhaps not surprising, since both are induced by IL-1, a proinflammatory monokine known to be present within rheumatoid synovium. However, a clear difference emerged between these serum proteins when the heightened acute phase response was one, not to chronic inflammation, but to multiple organ failure brought on by septic shock, severe trauma or ARDS. These patients had a greatly increased median serum concentration of CRP, whilst the proMMP-3 value was not significantly increased above control. Thus increased serum proMMP-3 appears at this time to be more a specific indicator of chronic inflammation, rather than just another marker of an acute phase response. The increased concentrations of plasma hyaluronic acid (HA) found in $\mathrm{RA}^{12}$ also may reflect synovial inflammation as, like proMMP-3, it is present in large amounts within SF and its synthesis is induced by IL-1 and TNF $\alpha$. In contrast to serum proMMP-3, 
however, increased plasma concentrations of $\mathrm{HA}$ were also obtained in $\mathrm{OA}$, and there was a considerable degree of overlap with the RA group. ${ }^{12} \mathrm{~A}$ further difference is that HA is also increased in septicaemia, ${ }^{13}$ a condition in which we have shown proMMP-3 was not increased.

Regarding the serum concentration of proMMP-3 in other chronic inflammatory diseases, roles for IL-1 and TNF $\alpha$ have also been proposed in the pathology of inflammatory bowel disease, and clinical trials of an IL-1 antagonist (IL-1Ra) have been initiated in patients with ulcerative colitis. ${ }^{14}$ In keeping with this, we have detected increased proMMP-3 serum concentrations in patients with ulcerative colitis and Crohn's disease (D J Taylor, P J Whorwell, unpublished observation). TNF $\alpha$ and matrix metalloproteinases have also been implicated in the destruction of myelin in multiple sclerosis. ${ }^{15}$ However, in several serum samples from three patients, serum proMMP-3 was within the normal range and showed no increase during relapse (D J Taylor, $\mathrm{N}$ Woodroofe, unpublished observation).

From these studies, the measurement of serum proMMP-3 appears to offer a convenient indicator of proinflammatory monokine action at sites of chronic inflammation. The availability of such a marker may prove useful in view of the current pharmacological attempts to inhibit the action or formation of these monokines in a number of chronic inflammatory diseases, including RA.

NOTE ADDED IN PROOF: While this paper was under review and after its acceptance, two other reports of increased serum proMMP-3 in RA were published. ${ }^{16} 17$

We thank surgeons $\mathrm{Mr} \mathrm{H}$ Bertfield, Mr T Dunningham, and Mr M A Morris for rheumatoid synovium and colleagues $\mathrm{Dr}$ $\mathrm{R}$ Clague and Dr I Campbell for serum and synovial fluid samples. Supported by Arthritis and Rheumatism Council grant W0124.
1 MacNaul $\mathrm{K} \mathrm{L}$, Chartrain $\mathrm{N}$, Lark $\mathrm{M}$, Tocci $M$ J, Hutchinson N I. Discordinate expression of stromeylsin, collagenase, and tissue inhibitor of metalloproteinases-1 in human rheumatoid synovial fibroblasts. Synergistic effects of interleukin-1 and tumour necrosis factor-alpha
on stromelysin expression. $\mathcal{F}$ Biol Chem 1990; 265: on strome

2 Unemori E N, Hibbs M S, Amento E P. Constitutive expression of a $92-\mathrm{kDa}$ gelatinase (Type $\mathrm{V}$ collagenase) by rheumatoid synovial fibroblasts and its induction in normal human fibroblasts by inflammatory cytokines. $f$ Clin Invest 1991; 88: 1656-62.

3 Okada Y, Morodomi T, Enghild J J, et al. Matrix metallproteinase 2 from human rheumatoid synovial fibroblasts. Eur F Biochem 1990; 194: 721-30.

4 Walakovits L, Moore V L, Bhardwaj N, Gallick G S, Lark M W. Detection of stromelysin and collagenase in synovial fluid from patients with rheumatoid arthritis and synovial fluid from patients with rheumatoid arthritis and posttra 42 .

5 Lohmander L S, Hoerrner L A, Lark M W. Metalloproteinases, tissue inhibitor and proteoglycan fragments in knee synovial fluid in human osteoarthritis. Arthritis Rheum 1993; 36: 181-9.

6 Matrisian L M. Metalloproteinases and their inhibitors in matrix remodelling. Trends Genet 1990; 6: 121-5.

7 Okada Y, Nagase H, Harris E D Jr. A metallproteinase from human rheumatoid synovial fibroblasts that digests connective tissue matrix components. $\mathcal{F}$ Biol Chem 1986; 261: 14245-55.

8 Lohmander L S, Neame P J, Sandy J D. The structure of aggregan fragments in human synovial fluid. Arthritis Rheum 1993; 36: 1214-22.

9 Arnett F C, Edworthy S M, Bloch D A, et al. The American Rheumatism Association 1987 revised criteria for the classification of rheumatoid arthritis. Arthritis Rheum 1988; 31: 315-24

10 Bennett P H, Burch T A. Clinical criteria for ankylosing spondylitis. In: Bennett P H, Wood P H N, eds. Population studies of the rheumatic diseases. Amsterdam: Excerpta Medica, 1968.

11 Baumann H, Prowse K R, Marinkovic S, Won K A, Jahreis G P. Stimulation of hepatic acute phase response by cytokines and glucocorticoids. Ann NY Acad Sci 1989; 557: $280-95$.

12 Goldberg R L, Huff J P, Lenz M E, Glickman P, Katz R, Thonar E J-M A. Elevated plasma levels of hyaluronate in patients with osteoarthritis and rheumatoid arthritis. Arthritis Rheum 1991; 34: 799-807.

13 Berg S, Brodin B, Hesselvik F, Laurent T C, Maller R. Elevated levels of plasma hyaluronan in septicaemia. Scand $\mathcal{~}$ Clin Lab Invest 1988; 48: 727-32.

14 Dinarello C A. Modalities for reducing interleukin-1 activity in disease. Immunol Today 1993; 14: 260-4.

15 Opdenakker G, Van Damme J. Cytokine-regulated proteases in autoimmune diseases. Immunol Today 1994; 15: 103-7.

16 Sasaki S, Iwata H, Ishigaro N, Obata K, Miara T. Detection of stromelysin in synovial fluid and serum from patients with rheumatoid arthritis and osteoarthritis. Clin Rheumatol 1994; 13: 228-33.

17 Baker T, Tickle S, Wasan H, Docherty A, Isenberg D, Waxman J. Serum metalloproteinases and their inhibitors: markers for malignant potential. Br f Cancer 1994; 70: ma6-12. 